\title{
Impacts of Sulfate Contamination on the Florida Everglades Ecosystem
}

\section{Introduction}

Water quality is a key issue facing the restoration of the Florida Everglades. For example, agriculturally derived phosphorus entering the Everglades has caused eutrophication of 6 to 10 percent of the ecosystem, resulting in changes in the native plant communities. Phosphorus contamination remains an important issue facing Everglades restoration, but recent work by the U.S. Geological Survey (USGS) has pointed to other water-quality issues critical to the overall health of the Everglades ecosystem.

Among the most important of these other water-quality issues in the Everglades is sulfate $\left(\mathrm{SO}_{4}^{2-}\right)$ contamination. Sulfate contamination affects as much as one-third of the freshwater Everglades, and sulfate concentrations are 60 to 100 times

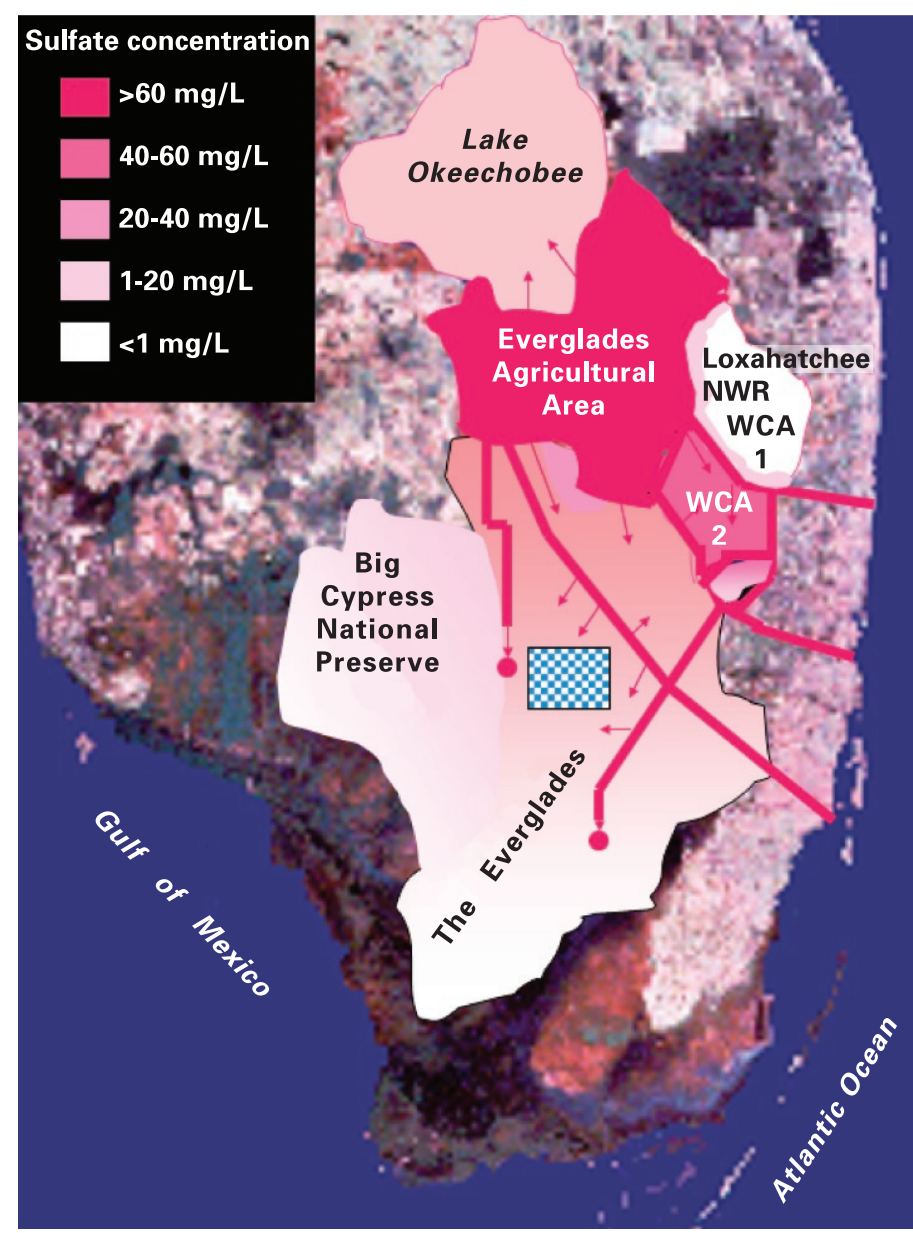

Figure 1. Map of the Everglades area, superimposed on a satellite image of South Florida, showing the distribution of sulfate contamination. The checkered area is currently the area of highest methylmercury production in the Everglades. NWR, National Wildlife Refuge; WCA, Water Conservation Area. Heavy lines indicate canals; large dots indicate terminal discharge areas; arrows indicate discharge points and leakage areas. historical levels in heavily affected areas. The effects of sulfate contamination on ecosystem health have not been fully studied, but links between sulfate contamination and high levels of methylmercury in the ecosystem have been documented. Also, sulfate contamination may be contributing to declines in native plants by altering chemical conditions in the sediments. Ongoing USGS research will further delineate these effects and explore possible options for mitigating sulfate contamination in this unique ecosystem.

\section{Sulfate in the Everglades}

Pristine areas of the freshwater Everglades have low concentrations of sulfate in surface water, typically 1 milligram per liter $(\mathrm{mg} / \mathrm{L})$ or 1 part per million $(\mathrm{ppm})$ or less. Historical levels of sulfate in the freshwater Everglades were probably also $1 \mathrm{mg} /$ L or less. Today, about one-third of the ecosystem has sulfate concentrations higher than $1 \mathrm{mg} / \mathrm{L}$, and some marsh areas have sulfate concentrations in excess of $60 \mathrm{mg} / \mathrm{L}$ (fig. 1). In general, sulfate concentrations decrease from north to south.

\section{Sources of Sulfate}

Figure 1 shows that the highest concentrations of sulfate in the freshwater Everglades are found in (1) canals in the Everglades Agricultural Area (EAA), (2) canals in the Everglades, and (3) marsh areas that receive direct discharge from these canals (especially in Water Conservation Area 2). Lake Okeechobee is the source of water for EAA canals and for much of the water entering the Everglades. The concentrations of sulfate in Lake Okeechobee, although elevated, are significantly lower than those in EAA canals. This information strongly indicates that canals within the EAA are the principal source of sulfate contamination in the Everglades. Much of the sulfate in Lake Okeechobee may also originate from the EAA, from the backpumping of canal water into the lake.

Sulfur isotopic composition can be used to trace the sources of sulfate contamination. This approach uses the ratio of different isotopes of sulfur $\left({ }^{34} \mathrm{~S}\right.$ and $\left.{ }^{32} \mathrm{~S}\right)$ in sulfate to trace its source. Figure 2 shows a plot of sulfate concentration versus sulfur isotope composition $\left(\delta^{34} \mathrm{~S}\right)$ for water samples from canals and Everglades marshes. At low concentrations, the sulfur isotope composition of sulfate varies over a wide range, indicating that multiple sources of sulfate are present. As sulfate concentrations increase, the sulfur isotope composition begins to form a trend line, indicating that one source is becoming dominant. The trend line points to a source having a sulfur isotope composition of about $15-16$ per mil, which is the sulfur isotope composition of agricultural sulfur used in the EAA as a soil amendment. These data, therefore, are consistent with agricultural sulfur as a major source of sulfate contamination in the Everglades. 


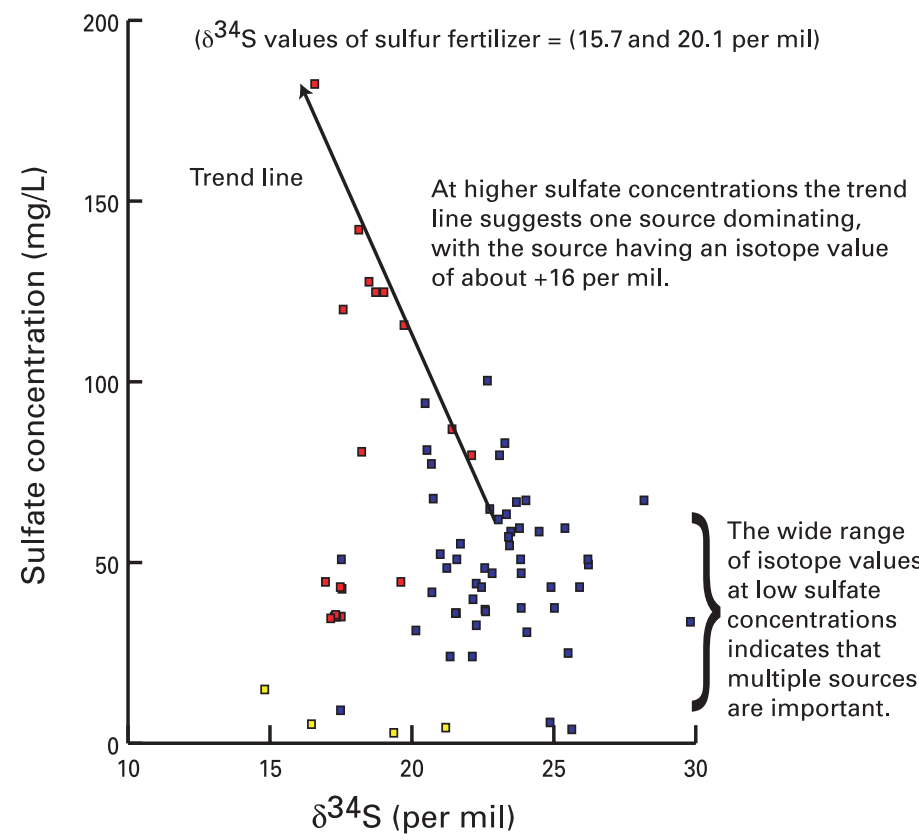

Figure 2. Plot of sulfate concentration and sulfur isotope composition $\left(\delta^{34} S\right)$, suggesting agricultural sulfur use within the Everglades Agricultural Area (EAA) as a major source of sulfate contamination to the Everglades. WCA, Water Conservation Area; mg/L, milligram per liter.

Figure 3 shows the major sources contributing sulfate to a heavily sulfur contaminated site in the Everglades. Rainfall and shallow ground water have sulfate concentrations too low to account for the high levels of sulfate in the marsh water. Deep ground water has high enough concentrations of sulfate to be a significant source, but its sulfur isotope composition and high content of chloride differ significantly from those of the marsh water. Clearly, EAA canal water is the best match, in terms of sulfate concentration and sulfur isotope composition, as the major source of sulfate contamination to the ecosystem (fig. 4).

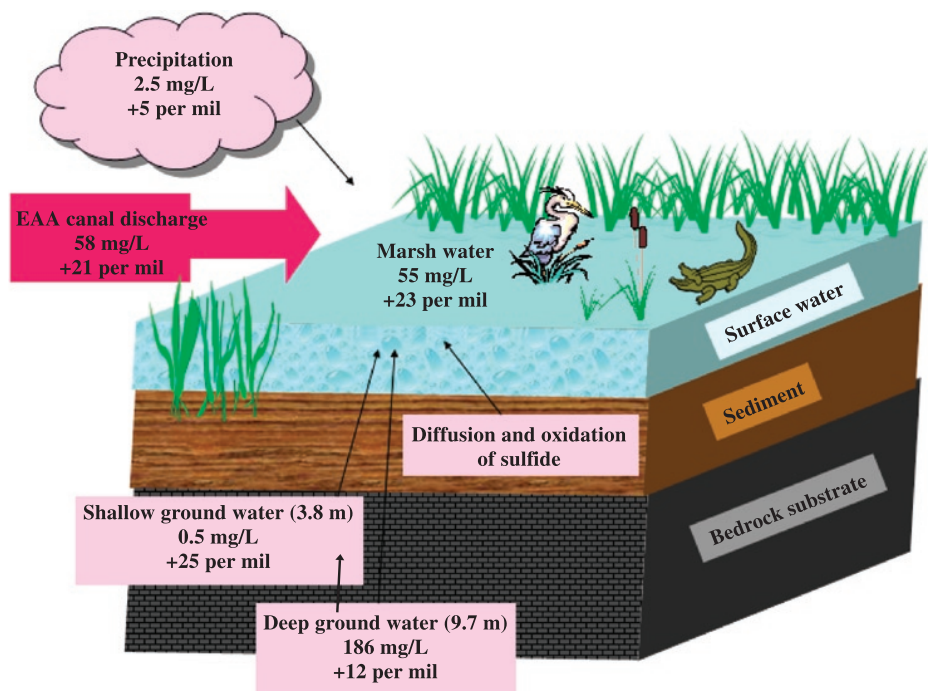

Figure 3. Sulfate sources at a heavily contaminated site, showing discharge of Everglades Agricultural Area (EAA) canal water as the major source. Sulfate concentration is measured in milligrams per liter ( $\mathrm{mg} / \mathrm{L}$ ); sulfur isotope composition is measured per mil.

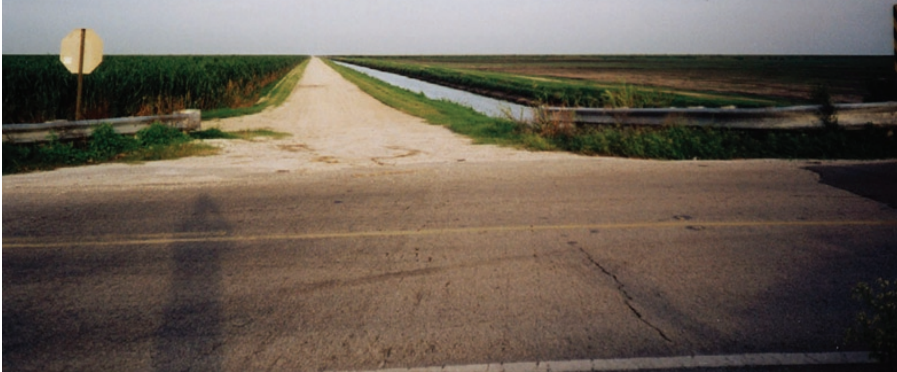

Figure 4. Canal and adjacent agricultural fields in the Everglades Agricultural Area. Photograph by William H. Orem.

\section{Sulfate Reduction}

Microbial sulfate reduction is an important biogeochemical process in the recycling of elements at the Earth's surface. Sulfate reduction takes place only under oxygen-free (anoxic) conditions, usually in sediments. Sulfate-reducing bacteria use sulfate instead of oxygen in their metabolism of organic matter; in the process, the bacteria change (reduce) sulfate to sulfide, a very reactive substance. Sulfide reacts with metals to form insoluble metal sulfides such as pyrite (fig. 5) and with organic matter to form organic sulfur compounds. Anyone who has ever visited a salt marsh may remember the "rotten egg" smell of the sulfide produced by sulfate reduction.

Sulfate reduction is a key process in marine environments where sulfate is abundant, but it is usually limited in freshwater wetlands by the low levels of sulfate. Sulfate contamination from EAA canal discharge, however, has greatly increased the rates of sulfate reduction in a large area of the Everglades. Pristine areas of the Everglades have virtually undetectable levels of sulfide in sediment pore water, but sulfate-contaminated areas have the "rotten egg" odor of sulfide present at levels 10,000 times background in the sediment (as measured with a sulfide electrode). The sulfur cycle for the Everglades is illustrated in figure 6 .

\section{The Methylmercury-Sulfate Connection}

Methylmercury (MeHg) is another major water-quality problem in the Everglades. MeHg is a neurotoxin that is bioaccumulated and found in high concentrations in fish and other wildlife in the Everglades. Fish consumption advisories have been posted throughout the Everglades by the Florida Department of Environmental Protection because of the danger that this neurotoxin poses to human health, especially to pregnant women. The $\mathrm{MeHg}$ problem is directly linked to sulfate contamination of the Everglades, because sulfate-reducing bacteria produce $\mathrm{MeHg}$ (fig. 6). Mercury enters the Everglades mainly in rainfall after atmospheric transport from human and natural sources (such as burning of fossil fuels, incineration of medical waste, volcanoes). The mercury raining on the Everglades is transformed to toxic $\mathrm{MeHg}$ by sulfate-reducing bacteria in sediments.

Sulfate entering the Everglades in canal discharge stimulates microbial sulfate reduction and $\mathrm{MeHg}$ production. There is a twist, however, in the MeHg-sulfate connection. Buildup of sulfide in sediment pore water actually inhibits $\mathrm{MeHg}$ production, 


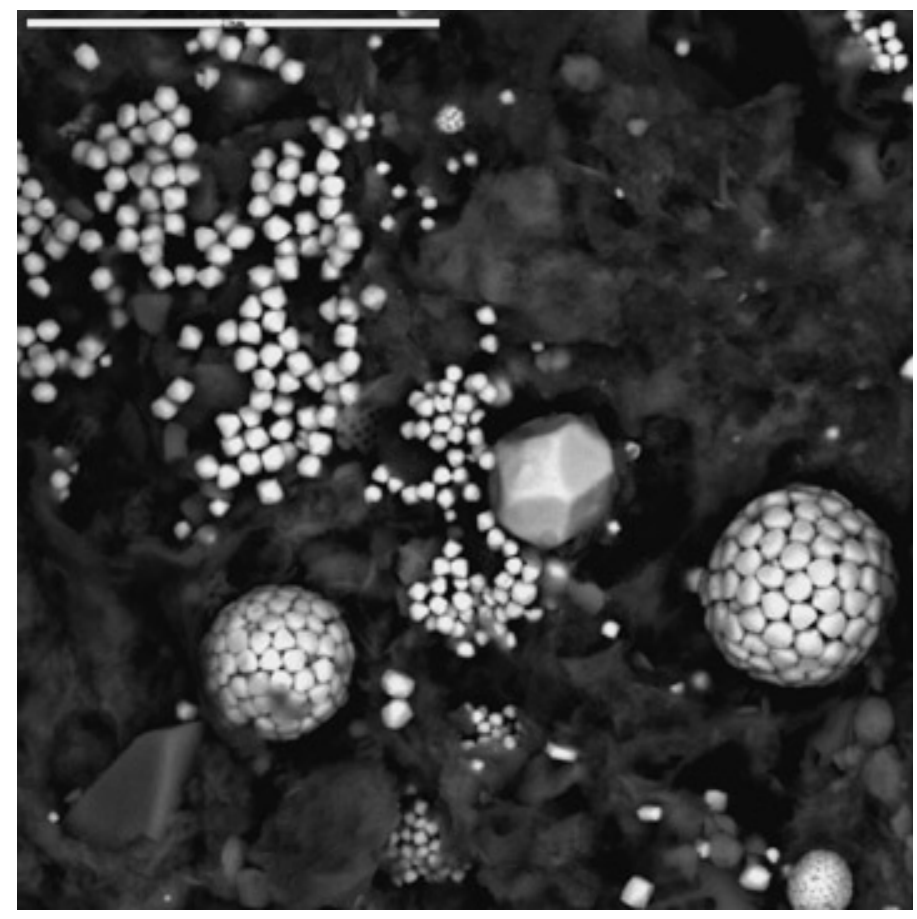

probably by making mercury less available to sulfate-reducing bacteria for $\mathrm{MeHg}$ production. Thus, sulfate stimulates production of $\mathrm{MeHg}$, but sulfide is an inhibitor. In the ecosystem, this relation plays out as follows (fig. 7):

(1) Heavily sulfate-contaminated areas have low to moderate $\mathrm{MeHg}$ production due to stimulation by sulfate, but inhibition by sulfide.

(2) Pristine areas have low $\mathrm{MeHg}$ production because low sulfate concentrations limit sulfate reduction.

(3) The areas of highest $\mathrm{MeHg}$ production occur where sulfate contamination is moderate $(2-10 \mathrm{mg} / \mathrm{L})$ and sulfide levels are low enough to avoid the inhibition of $\mathrm{MeHg}$ formation. The area of highest $\mathrm{MeHg}$ production in the Everglades is currently located near the center of Water Conservation Area 3 (the checkered area in fig. 1), where sulfate and sulfide concentrations are optimum for MeHg production.

Sulfate contamination of the Everglades and inputs of new mercury from rainfall appear to be the major factors influencing the intensity and distribution of $\mathrm{MeHg}$ production in the ecosystem.

Figure 5. Pyrite framboids $\left(\mathrm{FeS}_{2}\right)$ from sediments in Taylor Creek, near Lake Okeechobee. Bar scale equals 20 micrometers $(\mu \mathrm{m})$.

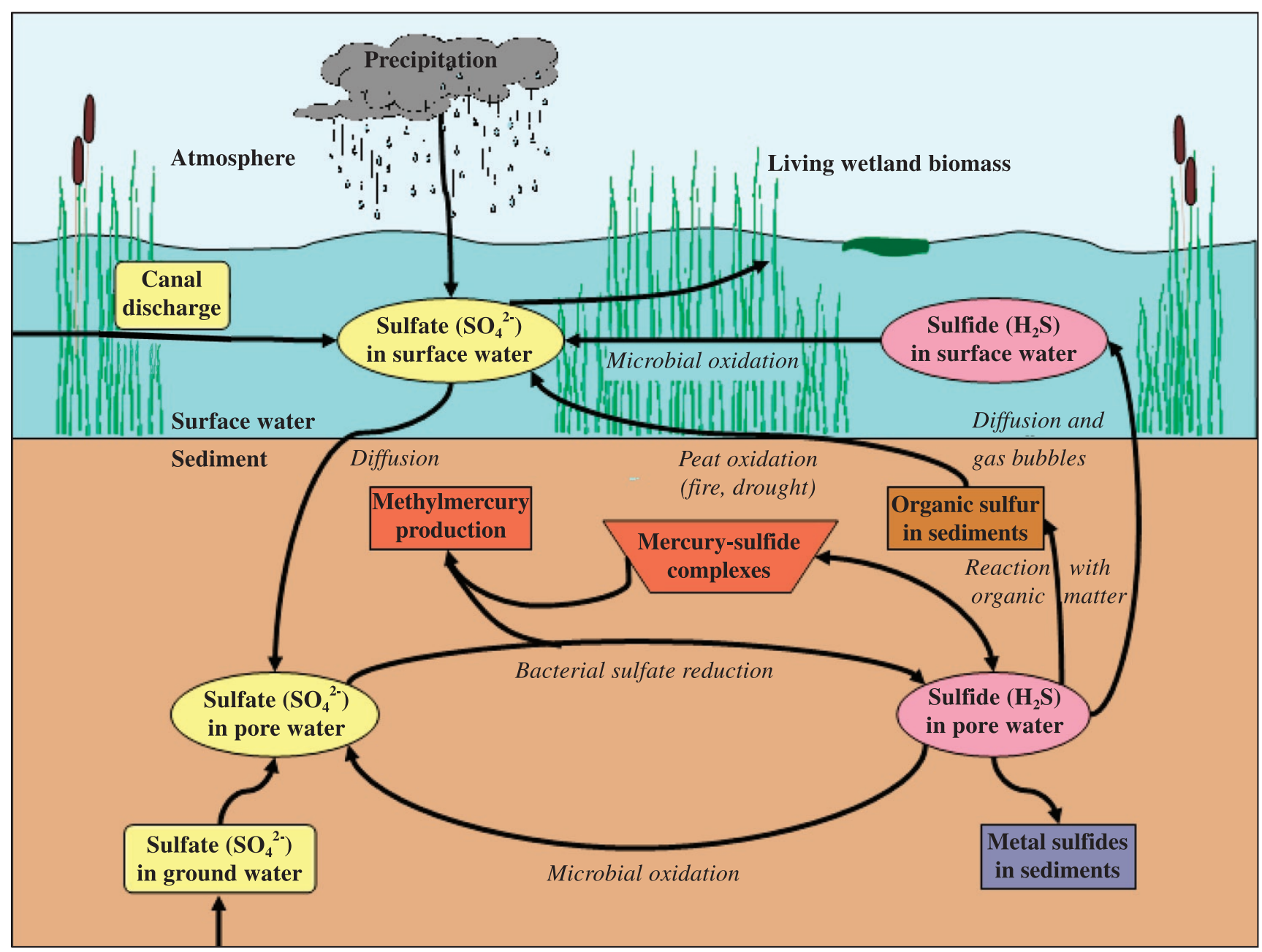

Figure 6. The Everglades sulfur cycle. Terms that are italicized (for example, Diffusion) are processes; bold type indicates interfaces. 


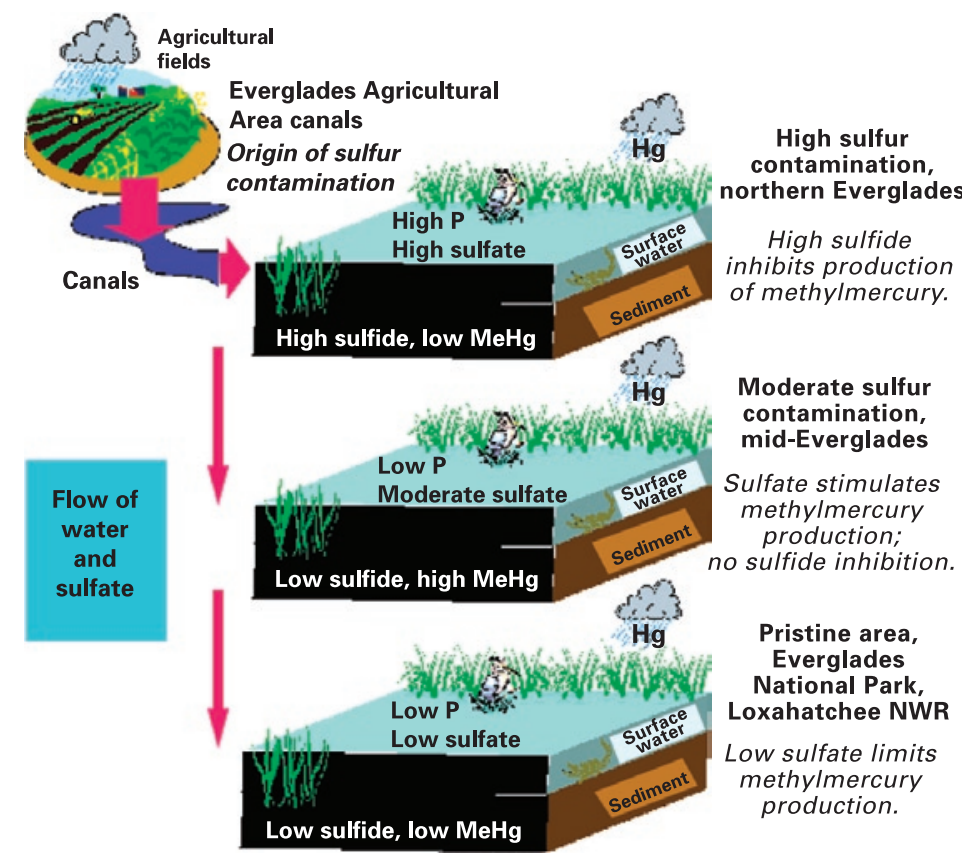

Figure 7. The methylmercury-sulfate connection in the Everglades. $\mathrm{Hg}$, mercury; P, phosphorus; MeHg, methylmercury; NWR, National Wildlife Refuge.

\section{Other Effects of Sulfate Contamination}

USGS studies have shown that areas of the Everglades heavily affected by sulfate contamination and resulting high sulfide levels in sediments have much lower sediment redox conditions than pristine sites. Lower redox conditions (a measure of sediment reducing capacity or available electron balance) can alter the natural chemical conditions in sediments, affect microbial activity, and decrease dissolved oxygen penetration into sediments. Studies in other freshwater wetlands suggest that high levels of sulfide (from sulfate contamination) may result in changes in the native plant communities. Numerous metals, some of which are important micronutrients for plants, react with high levels of sulfide to form insoluble chemical compounds that plants are unable to use. USGS scientists and academic collaborators are using environmental chambers (fig. 8) to study the effects of high levels of sulfate and resulting sulfide contamination on wetland plants native to the Everglades.

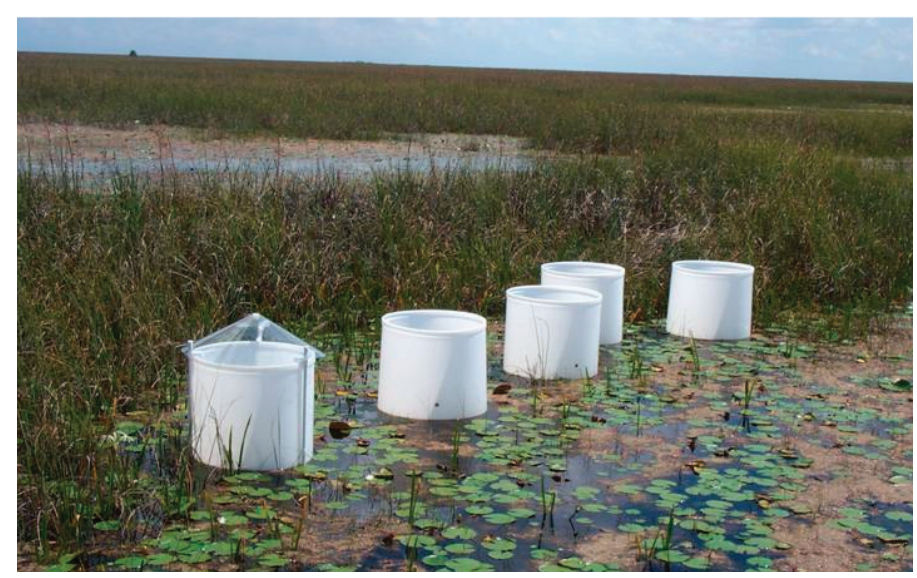

Figure 8. Experimental chambers in the Everglades used to study the effects of sulfate contamination. Photograph by William H. Orem.
Preliminary observations indicate a need to mitigate sulfate contamination of the Everglades.

\section{Sulfate Contamination and Everglades Restoration}

Restoration efforts aimed at improving water quality in the Everglades have focused primarily on reducing phosphorus contamination in the ecosystem. These efforts have included using (1) Best Management Practices (BMPs) to reduce the use of phosphorus fertilizer in the EAA and (2) Stormwater Treatment Areas, which are constructed wetlands designed to remove phosphorus from water before it is discharged to the Everglades. These approaches have greatly reduced the amount of phosphorus from the EAA discharged into the Everglades, although further progress is still needed.

Unfortunately, little has been done to reduce sulfate contamination of the ecosystem. Indeed, increasing the flow of water to the Everglades, which is a major goal of restoration, will likely increase the amount of sulfate entering the Everglades. An increase in the amount of sulfate entering the ecosystem could exacerbate the $\mathrm{MeHg}$ problem and other effects of sulfate on the ecosystem. Geochemical conceptual models also suggest that increasing amounts of sulfate entering the ecosystem could also move the zone of maximum $\mathrm{MeHg}$ production south from the central Everglades into Everglades National Park.

Implementation of BMPs for sulfur use in the EAA could significantly reduce the amount of sulfate entering the Everglades. BMPs for sulfur could include (1) reducing the amounts of agricultural sulfur used, (2) replacing agricultural sulfur with another soil amendment that would enhance phosphorus uptake by plants, and (3) using chloride instead of sulfate as the counter-ion in many fertilizers and other agricultural products. Unfortunately, Stormwater Treatment Areas appear to have little effect on reducing sulfate in agricultural discharge waters. Research on other approaches for mitigating sulfate inputs to the ecosystem is needed.

By William H. Orem

\section{For further information on sulfur contamination in the Everglades, please contact}

William H. Orem

U.S. Geological Survey

956 National Center

Reston, VA 20192

Telephone: 703-648-6273

E-mail : borem@usgs.gov

\section{For further information on mercury contamination in the Everglades, please contact}

David P. Krabbenhoft

U.S. Geological Survey

8505 Research Way

Middleton, WI 53562

Telephone: 608-821-3843

E-mail: dpkrabbe@usgs.gov 